\title{
Surgical management of dural arteriovenous fistulas with transosseous arterial feeders involving the jugular bulb
}

\author{
W. Tirakotai $\cdot$ L. Benes $\cdot$ C. Kappus $\cdot$ U. Sure $\cdot$ \\ A. Farhoud $\cdot$ S. Bien $\cdot$ H. Bertalanffy
}

Received: 14 March 2006/Revised: 2 September 2006 /Accepted: 3 September 2006 / Published online: 16 November 2006

(C) Springer-Verlag 2006

\begin{abstract}
Dural arteriovenous fistulas located in the vicinity of the jugular foramen are complex vascular malformations and belong to the most challenging skull base lesions to treat. The authors comprehensively analyze multiple features in a series of dural arteriovenous fistulas with transosseous arterial feeders involving the jugular bulb. Four patients who underwent surgery via the transcondylar approach to treat dural arteriovenous fistulas around the jugular foramen were retrospectively reviewed. Previously, endovascular treatment was attempted in all patients. The success of the surgical treatment was examined with postoperative angiography. Complete obliteration of the dural arteriovenous fistulas (DAVFs) was achieved in three patients, and significant flow reduction in one individual. All patients had a good postoperative outcome, and only one experienced mild hypoglossal nerve palsy. Despite extensive bone drilling, an occipitocervical fusion was necessary in only one patient with bilateral lesions. The use of an individually tailored transcondylar approach to treat dural arteriovenous fistulas at the region of the jugular foramen is most effective. This approach allows for complete obliteration of the connecting arterial feeders, and removal of bony structures containing pathological vessels.
\end{abstract}

Keywords Dural arteriovenous fistula .

Intraosseous DAVFs · Jugular bulb · Occipital condyle ·

Transcondylar approach $\cdot$ Transosseous arterial feeder

W. Tirakotai $(\bowtie) \cdot$ L. Benes $\cdot$ C. Kappus $\cdot$ U. Sure $\cdot$ A. Farhoud $\cdot$ H. Bertalanffy

Department of Neurosurgery, University Hospital Marburg,

35043 Marburg, Germany

e-mail: srwtr@yahoo.com

S. Bien

Department of Neuroradiology, University Hospital Marburg,

35043 Marburg, Germany

\section{Introduction}

Ten to $15 \%$ of intracranial arteriovenous fistulas are dural lesions [27], and these are most commonly related to dural venous sinuses [7]. Only a few previous articles have reported the less common intraosseous dural arteriovenous fistulas occurring at the anterior or posterior skull base [8, $19,22,26,30]$. Although the pathogenesis of dural arteriovenous fistulas (DAVFs) is not yet well understood, angiogenic factors and local hypoxia might play the most important roles in angiogenesis of DAVFs [24, 36-39]. The known experience suggests that the natural history of DAVFs is sometimes progressive, and intervention aiming at closure of these fisulas should be considered in selected cases - either surgically, endovascularly, or radiosurgically $[6,11,15,21]$. In some circumstances, successful obliteration may not be possible by endovascular means, or patients may refuse the radiosurgical treatment. Direct surgery may be the best treatment option in such cases.

Surgical treatment of the DAVFs at the jugular foramen region aims at removal of the bony parts that contain the pathological vessels, and physical interruption or obliteration of the arterialised leptomeningeal venous connection. In the patients we have treated so far, the fistula complex was located within or in the vicinity of the occipital condyle, rendering the suboccipital transcondylar approach as the best access route for surgical treatment. Several previous studies related to fistulas with transosseous arterial feeders dealt with endovascular embolization or with a similar surgical technique, but in many aspects different from ours $[14,20,21,26]$. It was the aim of the present study to detail our surgical technique for the treatment of DAVFs in the region of the jugular foramen, and to retrospectively review the clinical outcome of four patients treated at our institute during a 5-year period. 


\section{Patients and methods}

Patients

Between June 1999 and February 2004, four patients underwent surgery at the Department of Neurosurgery, Philipps University for removal of DAVFs involving the jugular foramen. Patients ranged in age from 58 to 72 years, with a mean of 67 years. There were three females and one male; one individual had bilateral lesions. Four lesions were located on the right, and one on the left side. All patients were symptomatic, the most common presenting symptom being pulsatile bruit. The clinical details are summarized in Table 1.

All patients underwent preoperative angiography and at least two attempts of endovascular embolization. For the occlusion of arterial feeders, Guglielmi electrolytically detachable platinum coils were used. The decision for surgical intervention was made after the endovascular approach proved unsuccessful in terms of complete obliteration, and the patient developed neurological deficits or intolerable symptoms of pulsatile bruit.

Case histories

Case 1 A 58-year-old male presented with a 1-year history of pulsatile tinnitus in the right ear. Neurological examination revealed a partial right-sided hypoglossal palsy. Superselective angiography disclosed multiple DAVFs between the distal right sigmoid sinus and transosseous arterial feeders from the right ascending pharyngeal and right occipital arteries. Although the endovascular intervention resulted in coil occlusion of the occipital artery, the DAVFs still persisted (Fig. 1). Microsurgical intervention was performed due to intolerable pulsatile tinnitus, with the patient in the sitting position. Only minimal bony involvement around the jugular foramen was detectable on the CT scan (Fig. 1).

Case 2 This 72-year-old female had suffered from pulsatile tinnitus in the right ear for more than 18 years. During this period, the patient was angiographically diagnosed as having DAVFs in the region of the right jugular bulb. Four sessions of endovascular intervention were performed without success. Several months before admission, the patient experienced a clinical deterioration in the form of right periorbital swelling. In addition, there was excessive lacrimation of the right eye, and progressive numbness occurred around her right ear. On the CT scan, a bony erosion of the medial portion of the right occipital condyle and jugular tubercle became evident. A recent angiography disclosed the typical early filling of the right jugular bulb, and right sigmoid and transverse sinuses through intraosseous DAVFs mainly supplied by both ascending pharyngeal arteries and both occipital arteries (Fig. 2). The patient subsequently underwent surgical intervention in the left park bench position (Fig. 2).

Case 3 A 70-year-old female presented with a 10-month history of bilateral pulsatile tinnitus predominant in the right ear. Neurological examination was irrelevant, and superselective angiography revealed numerous bilateral DAVFs in the foramen magnum region affecting both occipital condyles and jugular processes (Fig. 3). The fistula drained into both jugular veins, respectively. Feeding

Table 1 Summary of clinical features

\begin{tabular}{|c|c|c|c|c|c|c|c|}
\hline $\begin{array}{l}\text { Case } \\
\text { no. }\end{array}$ & $\begin{array}{l}\text { Age/ } \\
\text { sex }\end{array}$ & Presentation & Location & Embolization & Angiography & $\begin{array}{l}\text { Attempts and } \\
\text { interval }\end{array}$ & Outcome \\
\hline 1. WP & $58 Y / M$ & $\begin{array}{l}\text { Pulsatile bruit, rt. } \\
\text { hypoglossal nerve } \\
\text { paresis }\end{array}$ & $\begin{array}{l}\text { Rt. jugular process } \\
\text { and bulb }\end{array}$ & Yes & $\begin{array}{l}\text { Feeders: rt. ascending } \\
\text { pharyngeal and occipital } \\
\text { arteries of ECA }\end{array}$ & 2,2 days & $\begin{array}{l}\text { No additional } \\
\text { deficits; } \\
\text { symptom free }\end{array}$ \\
\hline 2. KW & $72 \mathrm{Y} / \mathrm{F}$ & $\begin{array}{l}\text { Pulsatile bruit, } \\
\text { swelling of rt. } \\
\text { upper and lower } \\
\text { eyelids }\end{array}$ & $\begin{array}{l}\text { Rt. jugular process } \\
\text { and bulb }\end{array}$ & Yes & $\begin{array}{l}\text { Feeders: Both ascending } \\
\text { pharyngeal and rt. } \\
\text { occipital arteries of ECA }\end{array}$ & 4, 5 days & $\begin{array}{l}\text { No deficits; } \\
\text { symptoms } \\
\text { improved }\end{array}$ \\
\hline 3. SH & $70 \mathrm{Y} / \mathrm{F}$ & Pulsatile bruit & $\begin{array}{l}\text { Dorsal rim of foramen } \\
\text { magnum, both occipital } \\
\text { condyles and jugular } \\
\text { processes }\end{array}$ & Yes & $\begin{array}{l}\text { Feeders: Both internal } \\
\text { maxillary and occipital } \\
\text { arteries of ECA }\end{array}$ & 2, 1 month & $\begin{array}{l}\text { No deficits, } \\
\text { symptom-free }\end{array}$ \\
\hline 4. BE & $68 \mathrm{Y} / \mathrm{F}$ & Pulsatile bruit & Rt. Jugular tubercle and bulb & Yes & $\begin{array}{l}\text { Feeders: rt. ascending } \\
\text { pharyngeal and occipital } \\
\text { arteries of ECA }\end{array}$ & 2,4 days & $\begin{array}{l}\text { Mild } \\
\text { hypoglossal } \\
\text { nerve palsy; } \\
\text { symptom-free }\end{array}$ \\
\hline
\end{tabular}

Abbreviations: Y: years; M: male; F: female; Rt: right; ECA: external carotid artery; Attempts and interval: attempts of endovascular embolization, and timing between the last endovascular and surgical treatment 


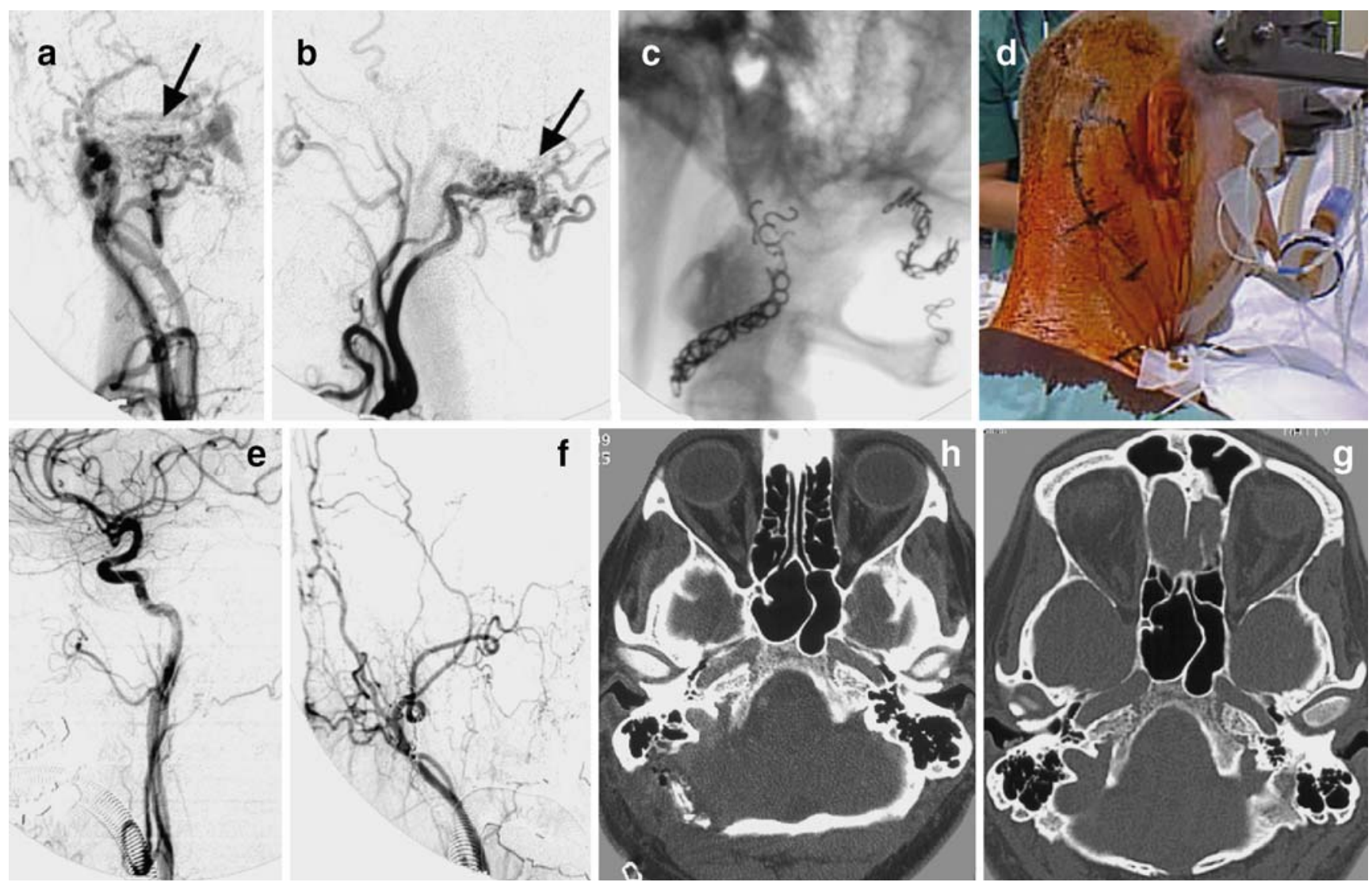

Fig. 1 DAVFs with transosseous arterial feeders. Right external carotid angiogram, antero-posterior (AP) (a) and lateral (b) views, demonstrate arteriovenous fistulas (arrows) adjacent to the right internal jugular bulb. The fistulas are mainly fed by the right-sided ascending pharyngeal and occipital arteries. Symptoms were improved following transarterial embolization with coils (c), but the fistulas persisted. Intraoperative photograph with the patient in the sitting position showing the electrodes for lower cranial nerve monitoring (d). Postoperative angiograms (e and $\mathbf{f}$ ) demonstrate cure of the DAVFs. The same patient's axial CT scan reveals the preoperative intraosseous lesion near the jugular process (g). Postoperative CT scan shows minimal bony removal (h) arteries were branches from the internal maxillary and occipital arteries. After partial occlusion of feeders on the right side, the intensity of the tinnitus decreased but still persisted. The patient was severely affected by this symptom. Surgery was therefore carried out using a right transcondylar exposure, and post-operatively the patient reported further improvement, with minimal residual tinnitus. During a 6-month follow-up, the intensity of left pulsatile bruit increased. Additionally, the patient developed a movement-related neck pain which proved to be caused by a fracture of the right occipital condyle, with dislocation of a bony fragment and craniocervical instability (Fig. 3). She underwent a second surgical procedure via a left transcondylar approach to treat the left DAVFs, followed by an occipitocervical fusion performed in the same surgical setting (Fig. 4).

Case 4 This 68-year-old female complained of progressive pulsatile right-sided tinnitus for 1 year. Neurological examination was irrelevant. An angiogram obtained at our institution furnished evidence of DAVFs at the right occipital condyle and jugular tubercle. The fistula was mainly fed by meningeal branches of the right occipital and ascending pharyngeal arteries. The patient underwent embolization of the right occipital artery, aimed at reducing the arterial supply. Due to persistent arteriovenous connection and impairment of the patient's quality of life, surgery was subsequently performed.

\section{Surgical technique}

All surgical procedures were performed by the senior author (H.B.). The first aim of surgery was an adequate exposure of the dorsolateral suboccipital region, including the medial portion of the occipital condyle, the lateral rim of the foramen magnum, the arch of the atlas and the horizontal portion of the vertebral artery, as well as the medial mastoid and particularly the jugular process region (Fig. 5). The patient was placed either in the sitting or in the lateral park bench position with the head flexed, turned to the ipsilateral and slightly tilted to the contralateral side. It 

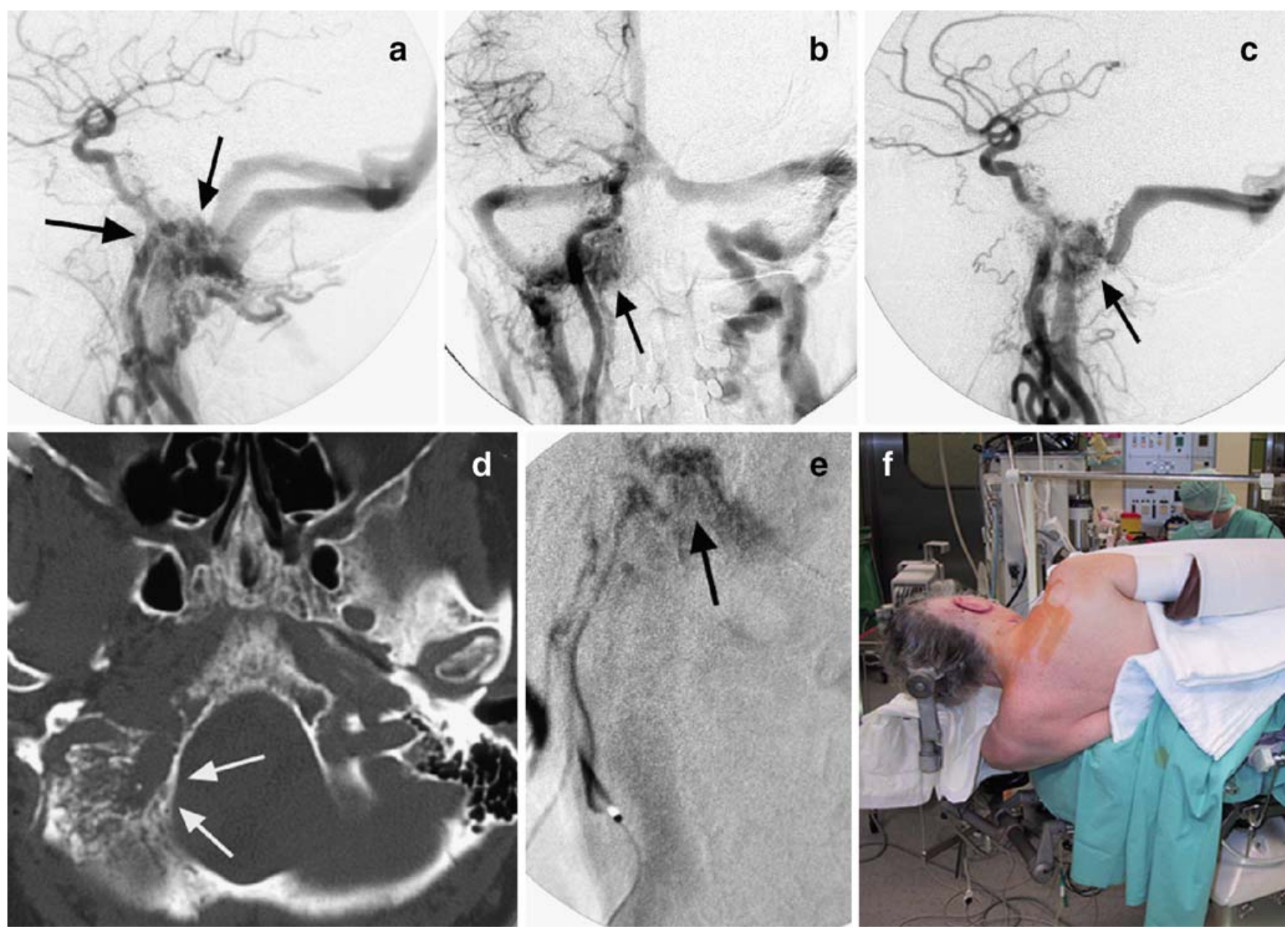

Fig. 2 Lateral (a) and AP (b) preoperative angiograms of the right common carotid artery (CCA), demonstrating the right intraosseous DAVFs (arrows). Postoperative right CCA angiogram revealing the remaining fistula (c). On the CT scan (d) bony erosion of the medial

portion of the right jugular tubercle becomes evident (white arrows). Selective injection of preoperative right occipital artery reveals intraosseous fistula (e). The patient is positioned in the left lateral park bench position (f)

was considered important to reduce the venous congestion by avoiding jugular-vein compression or by elevating the head when the lateral park bench position was chosen. Arterial feeders were occasionally encountered during muscular dissection in the course of the occipital artery in those patients in whom the artery has not been completely obliterated endovascularly before surgery.

First, a small dorso-lateral suboccipital craniectomy was performed, which basically corresponds to a dorso-lateral enlargement of the foramen magnum. Bone drilling began in the supracondylar fossa, and was extended both medially towards the rim of the foramen magnum and laterally towards the mastoid. By gradually exposing the distal sigmoid sinus and the dura mater of the suboccipital and upper cervical region, transosseous arterial feeders were encountered, which occasionally caused a brisk arterial bleeding (Fig. 6). To control this bony bleeding, drilling was temporarily performed using the diamond burrs without saline irrigation (Aesculap drills). Application of bone wax or bipolar coagulation to stop the bleeding was usually ineffective. In the patients with severe bony involvement, the consistency of the cancellous bone was remarkably altered. In these cases the bone marrow was packed with Surgicel and then slightly compressed with cottonoid to control the bleeding. In some cases, the arteriovenous fistulas involved the posterior condylar emissary vein located within/around the posterior condylar canal (Fig. 7). These bony portions were completely drilled away. While continuing drilling within the occipital condyle, the hypoglossal canal and the medial portion of the jugular bulb were gradually exposed. The medial wall of the jugular bulb, being the site of the arteriovenous fistulas, was coagulated to interrupt small arterial feeders of this area (Fig. 6).

Intraosseous DAVFs were also encountered around the hypoglossal canal, with arteriovenous shunts flowing into the venous plexus surrounding the hypoglossal canal, and more anteriorly in the region of the inferior petrosal sinus. To reach this area, the bony resection was extended into a deeper region. Use of the intraoperative microdoppler probe gave a 

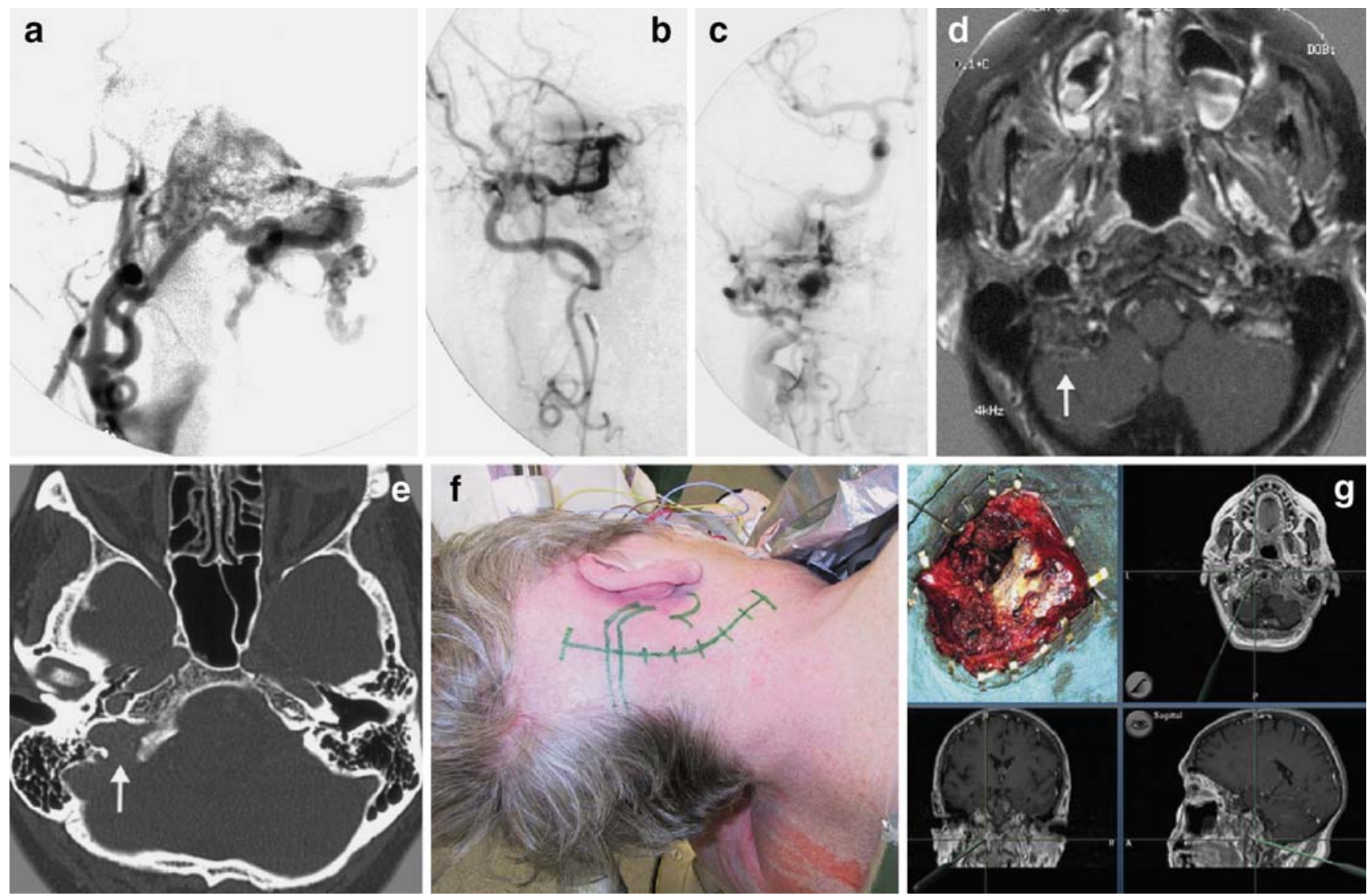

Fig. 3 Bilateral intraosseous DAVFs causing bilateral pulsatile tinnitus. Right lateral (a) and AP (b) external carotid angiograms, as well as right AP (c) common carotid angiogram demonstrate multiple arteriovenous shunts fed by the right internal maxillary and occipital arteries. MRI (d) and CT (e) studies show the abnormal vessels

posterior to the right jugular tubercle and the enlarged jugular foramen with its surrounding bony erosion, respectively (arrows). The photograph shows the skin incision for the right transcondylar approach (f). Intraoperative screenshot of navigation, applied for localizing the exent of the arteriovenous fistulas $(\mathbf{g})$

good impression of the arterialization of the jugular bulb. Thus, persistence of intraosseous arterial feeders indicated that bony resection had to be continued by drilling the jugular tubercle, the occipital condyle and the jugular process. The required extent of bone removal was also estimated from preoperative imaging, and was related to anatomical landmarks such as the hypoglossal canal, the posterior condylar emissary canal and the dural entrance of the vertebral artery. Drilling was stopped only when no more arterial feeders were encountered, indicating that all feeders had been interrupted. Normalization of blood flow within the jugular bulb could be documented by using the microdoppler probe. To adequately drill the dorsomedial portion of the occipital condyle, a small portion of the lateral atlantal mass had to be resected in some instances as well. In such cases, complete exposure of the horizontal portion of the vertebral artery was necessary. However, there was no need for complete $\mathrm{C} 1$ hemilaminectomy. The suboccipital dura mater was not opened, since an intradural inspection of the jugular foramen was unnecessary as there were no intradural arteriovenous shunts. After meticulous extradural hemostasis, wound closure was obtained in several layers.

\section{Results}

All four patients underwent surgical obliteration of their DAVFs via the transcondylar approach. This access route provided a good exposure of the target site, and allowed occlusion of the intraosseous pathological vessels. There were no intra-operative complications, and no permanent major postoperative deficit occurred. Despite a certain blood loss during surgery, no patient required intraoperative or postoperative blood transfusion. Although an extensive resection of the involved occipital condyle, jugular process and jugular tubercle was carried out in all patients, an occipito-cervical fusion was necessary only in patient 3 with bilateral lesions. There were no additional neurological deficits, with the exception of patient 4 , who experienced mild hypoglossal nerve palsy postoperatively.

Postoperative angiography was obtained in each patient to confirm obliteration of the DAVFs. Three patients showed radiological cures, with no further treatment necessary. In patient 2, the DAVFs were significantly reduced surgically, but still persisted. Therefore, a second surgical intervention 

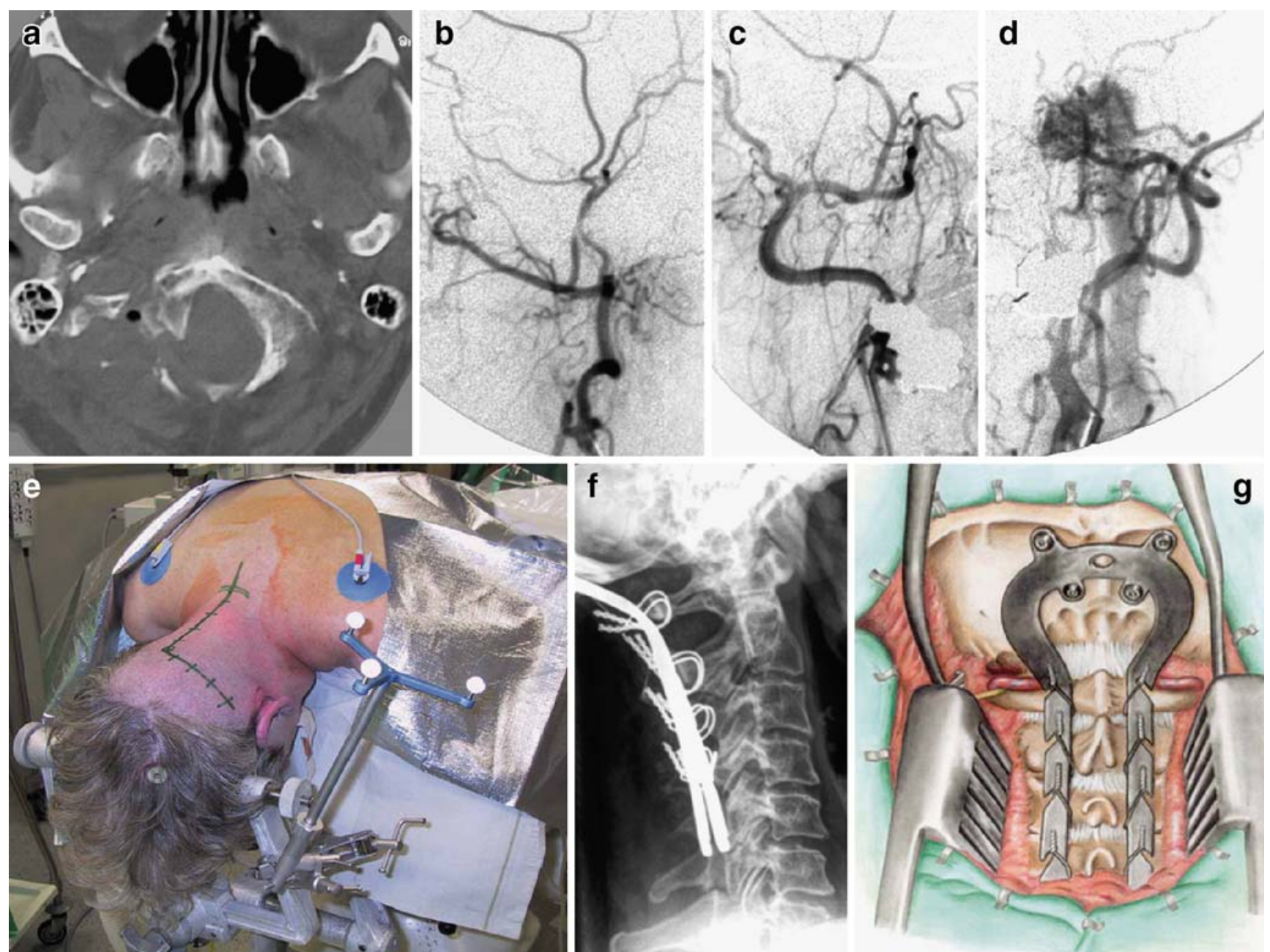

Fig. 4 Postoperative CT scan of the same patient shown in Fig. 3 reveals a fracture of the right occipital condyle with dislocation of a bony fragment (a). Postoperative angiograms of the right external carotid artery (ECA), lateral (b) and AP (c) views showing no arteriovenous fistula after the surgical resection of right intraosseous DAVFs. Preoperative angiogram of the left ECA revealing arterial

filling of the jugular vein and left-side DAVFs (d). The patient is placed in the prone position for the surgery of the left intraosseous DAVFs and the occipito-cervical fusion (e). Postoperative lateral plain radiogram (f) and a schematic drawing (g) demonstrating the instrumentation used for the occipitocervical fusion (g)

was proposed to the patient, who eventually refused. While preoperative complaints disappeared in three patients, they were clearly improved in one individual.

\section{Discussion}

Definition, terminology, pathology and symptoms

Dural arteriovenous fistulas [DAVFs] are defined as abnormal arteriovenous connections occurring within the leaflets of the dura mater, usually within or near the walls of a dural sinus [13]. Although the term "dural arteriovenous malformations" [DAVMs] has been used widely in the neuroscience literature, current nomenclatures include terms such as "DAVFs" and "dural arteriovenous shunts", according to an accepted view that many of these lesions are acquired $[7,9,10,18]$. Initially, DAVFs were described only in association with venous sinuses. Subsequently, they have been found in other locations such as the tentorium, the skull base and the intraorbital area as well [30, 31]. Piske and Lasjaunias hypothesized that DAVFs can develop wherever veins have their course [31]. This would explain why DAVFs can be located entirely within the bone, because emissary veins have transosseous courses. The particular group of dural arteriovenous fistulas located within the occipital condyle and jugular foramen region are intracavarial (intracranial) arteriovenous shunts fed by dural branches of both internal and external carotid arteries. Some authors have named this particular lesion "intraosseous DAVMs" [26] or "intraossous DAVFs" [22]. The fistulas are located within the bony structures surrounding the jugular bulb (the major draining vein), and may involve the adjacent draining veins $[8,26]$. 


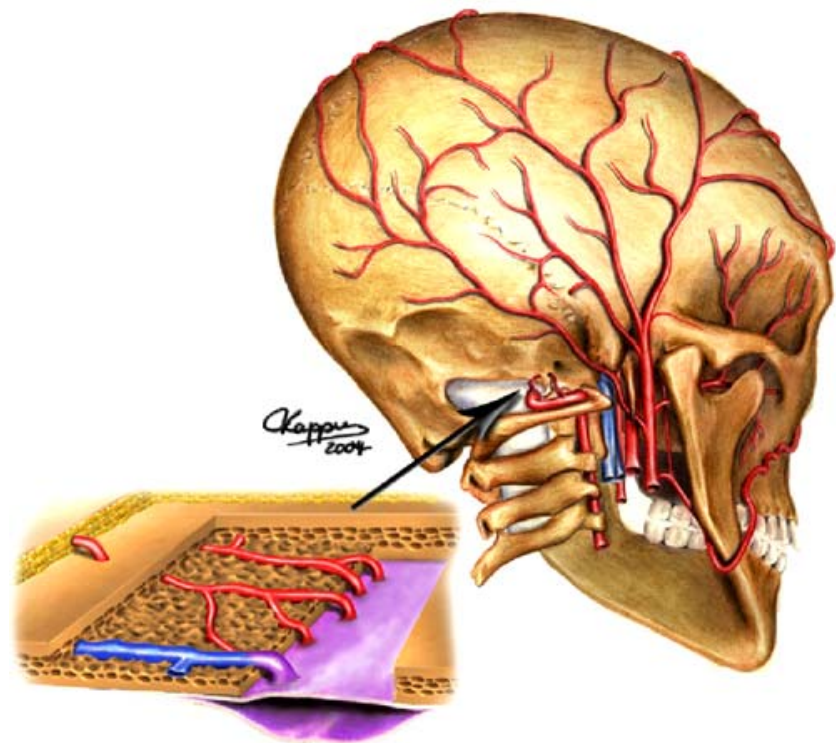

Fig. 5 The particular arteriovenous fistulas are located within the occipital condyle and the jugular foramen region. These fistulas are fed by dural branches of both internal and external carotid arteries (upper). The drawing demonstrates the intraosseous fistulas, arterialized diploic veins and draining vein (lower)

DAVFs involving the transverse and sigmoid sinuses always cause a pulsatile tinnitus [28, 29]. It seems that this symptom is related to venous turbulence in contact with the petrous bone, or to the high shunt flow into the petrosal sinus [22]. This might explain why all our patients presented with bruit as the predominant symptom.

\section{Imaging}

DAVFs are often invisible on CT and MR studies [17, 23]. Consequently, a normal contrast-enhanced CT or MR study does not exclude a DAVF. Contrary to the ordinary DAVFs, $\mathrm{CT}$ and MRI studies aid in giving the diagnosis of this particular DAVFs when the patient presents with pulsatile tinnitus due to demonstrable abnormal vessels in the soft tissue beneath the skull base [12, 32], or when bony erosion due to intraosseous abnormal vessels is present, as in the patients of our series. However, cerebral angiography remains the most important modality in evaluating DAVFs.

\section{General management and endovascular intervention}

According to current opinion, no single treatment is ideal for the obliteration of DAVFs, and management requires an interdisciplinary team approach which must be individualized for each patient. Malik et al. reported two patients with intraosseous dural arteriovenous fistulas located at the foramen magnum. He postulated that the intraosseous nature was related to the large number of emissary veins in this region, and recommended the exploration of the

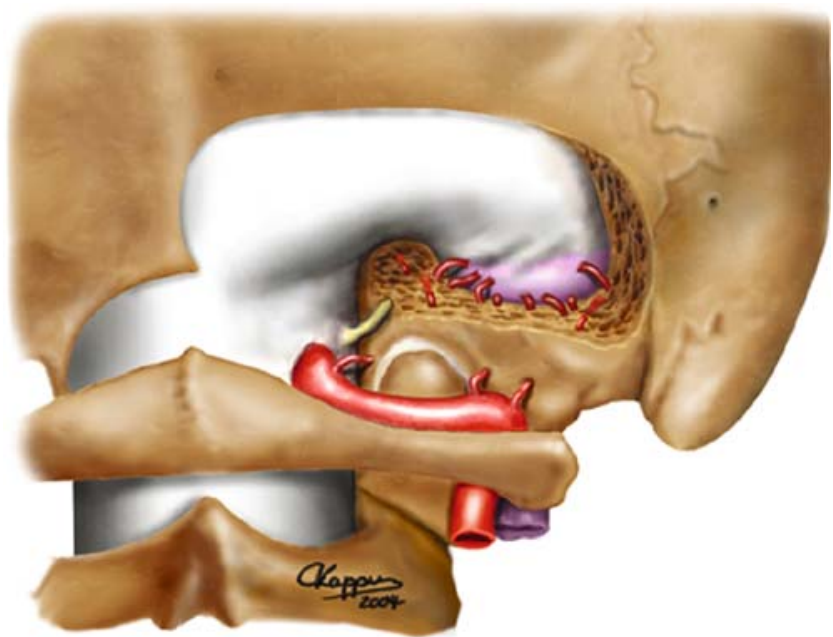

Fig. 6 Artistic illustration showing the transcondylar approach as applied to interrupt the connecting arterial feeders; the extent of the bony removal is judged according to the extent of the arteriovenous fistulas. Transosseous arterial feeders are encountered, which may occasionally cause a brisk arterial bleeding

adjacent bone until the entire fistula is exposed [26]. Our observations and intraoperative findings confirm this operative experience, that considerable but controllable hemorrhage can occur during bone removal.

As being less invasive than surgery, endovascular technique is given preference as the primary treatment. However, transvenous embolization or transarterial coil embolization of the ascending pharyngeal artery during

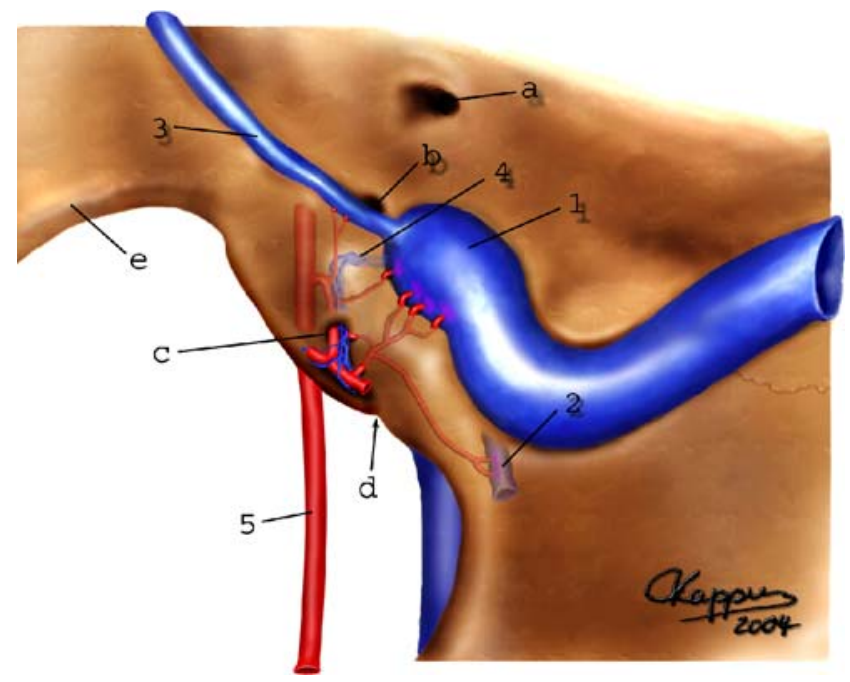

Fig. 7 Schematic drawing of intraosseous dural arteriovenous fistulas in the right hypoglossal canal and in the vicinity of the jugular foramen region. The feeders are the dural branches of the ascending pharyngeal artery. These arterial feeders connect with the inferior petrosal sinus, the jugular bulb and the posterior condylar emissary vein. (1: right jugular bulb, 2: right posterior emissary vein, 3 : right inferior petrosal sinus, 4: arterialized venous plexus within the right hypoglossal canal, 5: right ascending pharyngeal artery, $a$ : right internal auditory canal, $b$ : pars nervosa of the right jugular foramen, $c$ : right hypoglossal canal, $d$ : right occipital condyle, $e$ : anterior rim of the foramen magnum) 
treatment of hypoglossal DAVFs may sometimes be associated with complications [14, 22]. An alternative surgical therapy is warranted if the endovascular technique eventually fails, as it happened to all patients of this study. The reason for failure of the endovascular intervention is probably the great number of arterial feeders that traverse through the occipital condyle and jugular process to enter the jugular bulb. A transvenous embolization was not carried out in our patients, to avoid the risk of major venous occlusion. Although stereotactic radiosurgery either followed or not followed by transarterial particulate embolization of accessible external carotid feeding vessels became the primary mode of treatment at some institutions $[6,15$, $25,33]$, it may not always replace open surgery. Radiosurgery is expected to cause obliteration of DAVFs between 1 and 3 years after treatment [6], and it is not considered as a standard therapy for all types of DAVFs. Benign cranial DAVFs [6, 34], though, are a developing indication for radiosurgery [34]; stereotactic radiosurgery may be considered as an alternative treatment for this type of DAVFs that have failed other treatments [20].

Surgical technique and avoidance of complications

In the majority of our previously treated patients, we have used the juxtacondylar/transcondylar approach to expose various intradural craniospinal lesions $[1-5,16]$. To treat DAVFs, this approach was slightly modified, and primarily applied with the purpose of interrupting the pathological arterial feeders. The extent of bony resection at the skull base was, therefore, individually tailored according to the extent of arteriovenous fistulas under intraoperative microdoppler guidance.

The use of this surgical procedure was most effective, as all patients in our study showed postoperative clinical improvement, and complete obliteration of the intraosseous DAVF in three patients. Only one patient (patient 3), whose angiogram revealed residual $\mathrm{AV}$ fistulas, experienced previously developed mild periorbital edema. We believe that this was due to residual pathological vessels anterior to the jugular bulb, an area very difficult to reach surgically. During the removal of pathological bone containing abnormal fistulas in this patient, the dilated thin wall of the jugular bulb was slightly injured. After packing this area of venous bleeding with muscle fascia, no space for further drilling was available. A second, slightly-modified surgical intervention was, therefore, proposed to the patient to obliterate the remaining fistulas, but she refused.

Partial resection of the occipital condyle in DAVFs may be associated with the risk of injury to the vertebral artery and/or jugular bulb, or damage to the hypoglossal nerve. Since the arteriovenous fistulas may be located within and around the hypoglossal canal as in patient 4 of our series, the rootlets of the nerve may be injured by surgical manipulation, even in the hands of a very experienced neurosurgeon. Preoperative imaging with thin-slice CT scans or image fusion technique (which was applied in the last three patients) [35] can provide valuable information about the local topographical anatomy. This information comprises the variable anatomical configuration of the jugular tubercle, the course of the canal containing the posterior condylar emissary vein, and the size and exact location of arteriovenous fistulas.

Usually, the partial resection of the occipital condyle with opening of the atlanto-occipital joint does not create atlanto-occipital instability [2-5]. Only in the case of extensive bony drilling within the condyle, necessary due to the large number of transosseous pathological feeders, a partial condylar fracture may occur as it happened in patient 3 of this series. However, an occipito-cervical fusion was undertaken in this patient only because she harbored bilateral intraosseous DAVFs, and a second procedure on the opposite side was required that would have significantly destabilized the atlanto-occipital region.

\section{Conclusion}

Dural arteriovenous fistulas located around the jugular foramen are a less common type of DAVFs. The suboccipital transcondylar approach is considered the best access route when surgery of this particular pathology is intended. The amount of pathological bone that must be removed by drilling depends upon the extent of transosseous arterial feeders. Surgical obliteration of this complex vascular malformation is possible, at least in the cases in which the arterial feeders do not extend too far anterior to the jugular bulb. With this surgical technique, an atlanto-occipital instability may occur in very large or bilateral lesions, requiring occipito-cervical fusion.

Acknowledgement W. Tirakotai is a fellow of the Alexander von Humboldt Foundation, Bonn, Germany in the years 2005-2006.

\section{References}

1. Babu RP, Sekhar LN, Wright DC (1994) Extreme lateral transcondylar approach: technical improvements and lessons learned. J Neurosurg 81:49-59

2. Bertalanffy H, Benes L, Becker R, Aboul-Enein Hisham, Sure U (2002) Surgery of intradural tumors at the foramen magnum level. Oper Tech Neurosurg 5:11-24

3. Bertalanffy H, Gilsbach JM, Mayfrank L, Klein HM, Kawase T, Seeger W (1996) Microsurgical management of ventral and ventrolateral foramen magnum meningiomas. Acta Neurochir Suppl (Wien) 65:82-85 
4. Bertalanffy H, Seeger W (1991) The dorsolateral, suboccipital, transcondylar approach to the lower clivus and anterior portion of the craniocervical junction. Neurosurgery 29:815-821

5. Bertalanffy H, Sure U (2000) Surgical approaches to the jugular foramen. In: Robertson JT, Coakham HB, Robertson JH (eds) Cranial Base Surgey. Churchill Livingstone, London, pp 237-258

6. Brown RD, Flemming KD, Meyer FB, Cloft HJ, Pollock BE, Link MJ (2005) Natural history, evaluation and management of intracranial vascular malformations. Mayo Clin Proc 80:269-281

7. Chaudhary MY, Sachdev VP, Cho SH, Weitzner I Jr, Puljic S, Huang YP (1982) Dural arteriovenous malformation of the major venous sinuses: an acquired lesion. AJNR Am J Neuroradiol 3:13-19

8. Chen CJ, Wai YY, Wang LJ, Wong YC (2001) MRI of intraosseous dural arteriovenous malformation: findings in two cases. J Comput Assist Tomogr 25:133-136

9. Cognard C, Gobin YP, Pierot L, Bailly AL, Houdart E, Casasco A, Chiras J, Merland JJ (1995) Cerebral dural arteriovenous fistulas: clinical and angiographic correlation with a revised classification of venous drainage. Radiology 194:671-680

10. Davies MA, Saleh J, Ter Brugge K (1997) The natural history and management of intracranial dural arteriovenous fistulae. Part I: Benign lesions. Interv Neuroradiol 3:299-302

11. Davies MA, TerBrugge K, Willinsky R, Coyne T, Saleh J, Wallace MC (1996) The validity of classification for the clinical presentation of intracranial dural arteriovenous fistulas. J Neurosurg 85:830-837

12. Dietz RR, Davis WL, Harnsberger HR, Jacobs JM, Blatter DD (1994) MR imaging and MR angiography in the evaluation of pulsatile tinnitus. AJNR Am J Neuroradiol 15:879-889

13. Dion J (1993) Dural arteriovenous malformations: Definition, Classification, and Diagnostic Imaging. In: Awad IA, Barrow DL (eds) Dural arteriovenous malformation. American Association of Neurosurgical Surgeons, Illinois, pp 1-3

14. Ernst R, Bulas R, Tomsick T, van Loveren H, Aziz KA (1999) Three cases of dural arteriovenous fistula of the anterior condylar vein within the hypoglossal canal. AJNR Am J Neuroradiol 20:2016-2020

15. Friedman JA, Pollock BE, Nichols DA, Gorman DA, Foote RL, Stafford SL (2001) Results of combined stereotactic radiosurgery and transartetrial embolization for dural arteriovenous fistulas of the transverse and sigmoid sinuses. J Neurosurg 94:886-891

16. George B, Lot G, Tran Ba Huy P (1995) The juxtacondylar approach to the jugular foramen (without petrous bone drilling). Surg Neurol 44:279-284

17. Hasso AN (1994) Imaging of pulsatile tinnitus: basic examination versus comprehensive examination package. AJNR Am J Neuroradiol 15:890-892

18. Houser OW, Campbell JK, Campbell RJ, Sundt TM Jr (1979) Arteriovenous malformation affecting the transverse dural venous sinus-an acquired lesion. Mayo Clin Proc 54:651-661

19. Kattner KA, Roth TC, Giannotta SL (2002) Cranial base approaches for the surgical treatment of aggressive posterior fossa dural arteriovenous fistulae with leptomeningeal drainage: report of four technical cases. Neurosurgery 50:1156-1161

20. Kattner KA, Roth TC, Nardone EM, Giannotta SL (2004) The treatment of complex dural arteriovenous fistulae through cranial base techniques. Neurol India 52:325-331

21. Kim MS, Han DH, Kwon OK, Oh CW, Han MH (2002) Clinical characteristics of dural arteriovenous fistula. J Clin Neurosci 9:147-155

22. Kim MS, Oh CW, Han DH, Kwon Ok, Jung HW, Han MH (2002) Intraosseous dural arteriovenous fistula of the skull base associated with hearing loss. Case report. J Neurosurg 96:952955
23. Koenigsberg RA (1996) Spontaneous pulsatile tinnitus secondary to a dural malformation not visualized by magnetic resonace angiography. Clin Imaging 20:95-98

24. Lawton MT, Jacobwitz R, Spetzler RF (1997) Redefined role of angiogenesis in the pathogenesis of dural arteriovenous malformations. J Neurosurg 87:267-274

25. Link MJ, Coffey RJ, Nichols DA, Gorman DA (1996) The role of radiosurgery and particulate embolization in the treatment of dural arteriovenous fistulas. J Neurosurg 84: 804-809

26. Malik GM, Mahmood A, Mehta BA (1994) Dural arteriovenous malformation of the skull base with intraosseous vascular nidus. Report of two cases. J Neurosurg 81:620-623

27. Newton TH, Cronqvist S (1969) Involvement of dural arteries in intracranial arteriovenous malformations. Radiology 93: 1071-1078

28. Olteanu-Nerbe V, Uhl E, Steiger HJ, Yousry T, Reulen HJ (1997) Dural arteriovenous fistulas including the transverse and sigmoid sinuses: results of treatment in 30 cases. Acta Neurochir (Wien) 139:307-318

29. Osborn AG (1999) Diagnostic cerebral angiography. Lippincott Williams \& Wilkins, Philadelphia pp 300-310

30. Pierot L, Chiras J, Meder JF, Rose M, Rivierez M, Marsault C (1992) Dural arteriovenous fistulas of the posterior fossa draining into subarachnoid veins. AJNR Am J Neuroradiol 13:315-323

31. Piske RL, Lasjaunias R (1988) Extrasinusal dural arteriovenous malformations. Report of three cases. Neuroradiology 30:426-432

32. Roy D, Lavigne F, Raymond J (1993) Pulsatile tinnitus and dural arteriovenous fistula of the transverse sinus. J Otolaryngol 22:409-412

33. Shin M, Kurita H, Tago M, Kirino T (2000) Stereotactic radiosurgery for tentorial dural arteriovenous fistulae draining into the vein of Galen: report of two cases. Neurosurgery 46: 730-733

34. Steiger HJ, Hanggi D, Schmid-Elsaesser R (2005) Cranial and spinal dural arteriovenous malformations and fistulas: an update. Acta Neurochir Suppl 94:115-122

35. Sure U, Benes L, Riegel T, Schulte DM, Bertalanffy H (2002) Image fusion for skull base neuronavigation. Technical note. Neurol Med Chir (Tokyo) 42:458-462

36. Terada T, Tsuura M, Komai N, Higashida RT, Halbach VV, Dowd CF, Wilson CB, Hieshima GB (1996) The role of angiogenic factor bFGF in the development of dural AVFs. Acta Neurochir (Wien) 138:877-883

37. Tirakotai W, Bian LG, Bertalanffy H, Siegfried B, Sure U (2004) Immunohistochemical study in dural arteriovenous fistula and possible role of ephrin-B2 for development of dural arteriovenous fistula. Chin Med J (Engl) 117:1815-1820

38. Tirakotai W, Bertalanffy H, Liu-Guan B, Farhoud A, Sure U (2005) Immunohistochemical study in dural arteriovenous fistulas and possible role of local hypoxia for the de novo formation of dural arteriovenous fistulas. Clin Neurol Neurosurg 107:455-460

39. Uranishi R, Nakase H, Sakaki T (1999) Expression of angiogenic growth factors in dural arteriovenous fistula. J Neurosurg 91: 781786

\section{Comments}

Ossama Al-Mefty, Little Rock, USA

Dural arteriovenous fistulas remain baffling in their pathogenesis and controversial in their treatment. Those located at the jugular bulb with intraosseous arterial feeders are particularly rare and uniquely challenging to treat. The authors are to be commended for not only reporting a series of this disorder, but clearly demonstrating the 
effectiveness of the surgical therapy and detailing their techniques that are built on their masterful expertise in the transcondylar approach and vast experience in the treatment of lesions at the foramen magnum. As the authors found, endovascular treatment through the arterial side frequently fails to eliminate the lesion leading to opting for treatment through the venous route. While it is successful at times it is pathophysiologically concerning, since it is believed that venous thrombosis by itself is an underlying cause of the development of arteriovenous malformations (see references 1 and 2 at the end of this comment). Hence, maintaining venous sinus patency, especially in open sinus, by the surgical isolation of the fistula is certainly attractive method and the author has proven it effective.

\section{References}

1. Al-Mefty O, Jinkins JR, Fox JL (1986) Extensive dural arteriovenous malformation. Case Report. J Neurosurg 65:417-420

2. Arnautovic KI, Al-Mefty O, Angtuaco E, Phares L (1998) Dural arteriovenous malformation of the transverse-sigmoid sinus acquired from dominant sinus occlusion by a tumor: report of two cases. Neurosurgery $42: 383-388$

Bernard George, Emmanuel Houdart, Paris, France

This is a nice paper dealing with four cases of an exceptional location of intracranial arteriovenous fistulas (AVF). These four cases were treated surgically, with apparently complete exclusion in three cases. The authors have to be commended for the quality of surgery. They were using a lateral approach in all their cases. However, this aggressive type of treatment (leading to instability of the craniocervical junction in one case) might probably have been avoided. Our first comment is about the analysis of the AVF, which needs a complete angiographic work-up, with global as well as superselective catheterism of every external carotid artery (ECA) and vertebral artery (VA) branches. On figures presented here, there is no selective injection, and pictures are too small for a perfect analysis of (1) all the supplying branches, and (2) the exact site of the AVF. These AVF may in fact be developed in the wall of the jugular bulb but also of some connecting veins including the marginal sinus (case 4 could be one of these last locations). Then - and as a consequence of the previous comment - if arterial embolization is chosen, it should be realized very distally after superselective catheterization of the arterial pedicles. In this report, the main trunk of the arteries using coils was embolized. This corresponds to a proximal surgical ligation which —as has been known for a long time - has absolutely no chance of success. On the contrary, it will induce the development of more collateral arterial feeders and make the treatment (whatever it is) still more difficult. Today, arterial embolization using histoacryl material is applied only in simple AVF, with one single or very few arterial feeders. Quite recently, the use of a new material (Onyx) has given some more place to arterial embolization as this material can better reach the junction between arteries and the vein of drainage. In the vast majority of cases, intracranial AVFs, most commonly located on the sigmoid sinus and the cavernous sinus, are treated from the venous side with venous occlusion. So, in the cases reported here, if the AVF is located on the marginal sinus or on the distal part of the sigmoid sinus-jugular bulb with good contralateral venous drainage, the venous drainage can be sacrified. In the cases presented here, there is no venous phase on the pictures of post-operative angiographic controls; it may be possible that for some cases the surgery has also produced a venous occlusion, which explains the operative success. If the sigmoid sinus-jugular bulb occlusion cannot be compensated by the controlateral sigmoid sinus, arterial embolization with Onyx has to be attempted; in the case of failure of this endovascular techniqueand only in this case-surgical treatment can be discussed. For some patients with AVF presenting no risks of intracerebral lesions, in particular hemorrhage but complaining of tinnitus, surgery may appear too aggressive. Even for surgeons such as the authors of this paper, mastering the surgical technique of lateral approaches to the craniocervical junction, surgery may be considered a too important treatment. Therefore, this paper demonstrates the possibility of surgical cure of this particular location of dural AVF; however, in our opinion, with the progress of endovascular techniques, a less invasive treatment should initially be attempted. 